\title{
Recent studies with electrons, positrons and positronium ${ }^{\star}$
}

\author{
Michael J. Brunger ${ }^{1,2, a}$, David B. Cassidy ${ }^{3}$, Saša Dujko ${ }^{4}$, Dragana Marić ${ }^{4}$, Joan Marler ${ }^{5}$, James P. Sullivan ${ }^{6}$, and \\ Juraj Fedor ${ }^{7}$ \\ 1 College of Science and Engineering, Flinders University, GPO Box 2100, Adelaide 5001, SA, Australia \\ 2 Department of Actuarial Science and Applied Statistics, Faculty of Business and Information Science, UCSI, Kuala Lumpur \\ 56000, Malaysia \\ 3 Department of Physics and Astronomy, University College London, Gower Street, London WC1E 6BT, UK \\ 4 Institute of Physics, University of Belgrade, Pregrevica 118, Belgrade 11080, Serbia \\ 5 Department of Physics and Astronomy, Clemson University, Columbia 29634-0978, SC, USA \\ 6 Plasma Research Laboratories, The Research School of Physics, Australian National University, Canberra 0200, ACT, \\ Australia \\ 7 J. Heyrovský Institute of Physical Chemistry, Dolejškova 2155/3, Prague, Czech Republic
}

Received 15 May 2020

Published online 23 July 2020

(c) EDP Sciences / Società Italiana di Fisica / Springer-Verlag GmbH Germany, part of Springer Nature, 2020

\begin{abstract}
The latest rendition of the POSMOL conference, being comprised of the 20th International Workshop on Low-energy Positron and Positronium Physics and the 21st International Symposium on Electron-Molecule Collisions and Swarms, was successfully held at the Serbian Academy of Arts and Sciences, Belgrade, from July 18th to 20th 2019. Immediately thereafter, a one day workshop in honour of Professor Zoran Lj. Petrović, to acknowledge his many scientific contributions over a very distinguished career and to celebrate his retirement, was also held. This topical issue showcases contributions that encompass original research papers and topical reviews, on themes consistent with both POSMOL and the Workshop, as well as further contributions from the wider POSMOL community.
\end{abstract}

\section{Summary}

POSMOL 2019 was held in the lovely city of Belgrade, Serbia, from July 18th to 20th 2019. This was followed by a one day workshop that acknowledged and honoured the many scientific achievements of Professor Zoran Lj. Petrović, on the occasion of his retirement. A total of 153 delegates attended the meeting, making it one of the largest of the official satellites of ICPEAC. ${ }^{1}$ Considering the gender of the participants, we find that there were 37 female and 116 male delegates, and of those 42 people were $\mathrm{PhD}$ students with 111 delegates being regular participants. The program of POSMOL 2019 consisted of plenary lectures, invited talks, hot topic talks and posters, with a selection of that work, and from submissions from the wider POSMOL family, forming the basis of the present topical issue [1-24].

This topical issue contains contributions from all the elements that comprise the POSMOL community, namely

\footnotetext{
* Contribution to the Topical Issue "Low-Energy Positron and Positronium Physics and Electron-Molecule Collisions and Swarms (POSMOL 2019)", edited by Michael Brunger, David Cassidy, Saša Dujko, Dragana Marić, Joan Marler, James Sullivan, Juraj Fedor.

a e-mail: michael.brungerl@flinders.edu.au

1 See http://www.icpeac.2019.fr
}

atomic and molecular physics, gaseous electronics, lowtemperature plasma physics, astrophysics and medical physics. Accepted papers covering experimental, computational and theoretical contributions in these areas related to electron, positron, positronium, and swarm physics illustrate the current focus of the field, with several contributed topical reviews $[12,16,18,22]$ highlighting progress made up to now. Specifically, positron and positronium scattering or structure calculations on a range of targets were reported by Barp and Arretche [1], Hervieux and Chakraborty [3], Ellis-Gibbings et al. [4], Arretche et al. [5], Tenfen et al. [10], Seidel and Arretche [11], DeMars et al. [14], Ono et al. [23], and Yazejian and Straton [24]. A comprehensive series of electron scattering, both theoretical and experimental, contributed topical reviews, covering a very wide variety of molecules, were contributed by Scarlett et al. [12], Gorfinkiel [16], Song et al. [18], and Lopes et al. [22]. Original electron scattering articles, for a variety of scattering processes including dissociative electron attachment, are addressed in the papers of Jureta et al. [7], Tamuliene et al. [8], Orel and Larson [9], Moreira et al. [13], Ram et al. [15], and Demes et al. [17]. The swarm community also contributed original work, including Monte Carlo simulation results [21], from Simonović et al. [19], Sivoš et al. [20], and Puač et al. [21] to this topical issue. Finally, some 
modelling study results from Campbell et al. [2], on the atmosphere of Jupiter, and Nyffenegger-Pere and Cocks [6], on plasma diagnostic opportunities from a positron beam, round out this volume.

The next POSMOL conference will be held at the University of Notre Dame, Notre Dame in Indiana, the USA, on July 29th-August 1st, 2021. It will be the 9th joint meeting of the International Workshop on Low-Energy Positron and Positronium Physics and the International Symposium on Electron-Molecule Collisions and Swarms, satellite meetings of the International Conference on Photonic, Electronic, and Atomic Collisions (ICPEAC), that will be held in Ottawa, Canada, on July 20th-27th, 2021.

The POSMOL 2021 meeting will cover a wide range of research topics related to positron, electron, positronium and antimatter interactions with particles, atoms, molecules and complex systems as well as related subjects. The meeting will continue the tradition of a scientific forum at which a diverse group of scholars from around the world will have an opportunity to share their theoretical and experimental findings, ideas, innovations, and methodologies through the formal and informal discussions in order to advance scientific knowledge and understanding of the fundamental, collisional interactions.

The international scientific committees of POSMOL thank the local organising committee for the very hard work that they put in to make the Belgrade meeting such a great success. They also thank the major meeting sponsors: Serbian Ministry of Education, Science and Technology Development, the Serbian Academy of Arts and Sciences and the European Physical Journal D. Finally, we thank Associate Professor Sylwia Ptasińska for providing details of the POSMOL 2021 meeting.

Publisher's Note The EPJ Publishers remain neutral with regard to jurisdictional claims in published maps and institutional affiliations.

\section{References}

1. M.V. Barp, F. Arretche, Eur. Phys. J. D 73, 244 (2019)
2. L. Campbell, D.B. Jones, R.D. White, G. García, O. Ingólfsson, M.C.A. Lopes, M.J. Brunger, Eur. Phys. J. D 73, 252 (2019)

3. P.A. Hervieux, H.S. Chakraborty, Eur. Phys. J. D 73, 262 (2019)

4. L. Ellis-Gibbings, F. Blanco, G. García, Eur. Phys. J. D 73, 266 (2019)

5. P. Arretche, M.V. Barp, E.P. Seidel, W. Tenfen, Eur. Phys. J. D 74, 1 (2020)

6. Y. Nyffenegger-Pere, D. Cocks, Eur. Phys. J. D 74, 6 (2020)

7. J.J. Jureta, B.P. Marinković, L. Avaldi, Eur. Phys. J. D 74, $12(2020)$

8. J. Tamuliene, L. Romanova, V. Vukstich, A. Snegursky, Eur. Phys. J. D 74, 13 (2020)

9. A. Orel, Å. Larson, Eur. Phys. J. D 74, 15 (2020)

10. W. Tenfen, M.V. Barp, F. Arretche, Eur. Phys. J. D 74, $30(2020)$

11. E.P. Seidel, F. Arretche, Eur. Phys. J. D 74, 34 (2020)

12. L.H. Scarlett, J.S. Savage, D.V. Fursa, I. Bray, M.C. Zammit, Eur. Phys. J. D 74, 36 (2020)

13. G.M. Moreira, T.C. Freitas, M.H.F. Bettega, Eur. Phys. J. D 74, 46 (2020)

14. C.M. DeMars, J.B. Kent, S.J. Ward, Eur. Phys. J. D 74, $48(2020)$

15. N.B. Ram, V.S. Prabhudesai, E. Krishnakumar, Eur. Phys. J. D 74, 49 (2020)

16. J.D. Gorfinkiel, Eur. Phys. J. D 74, 51 (2020)

17. S. Demes, V. Kelemen, E. Remeta, Eur. Phys. J. D 74, 57 (2020)

18. M.Y. Song, J.S. Yoon, H. Cho, G.P. Karwasz, V. Kokoouline, Y. Nakamura, J. Tennyson, Eur. Phys. J. D 74, 60 (2020)

19. I. Simonović, D. Bošnjaković, Z.L. Petrović, R.D. White, S. Dujko, Eur. Phys. J. D 74, 63 (2020)

20. J. Sivoš, D. Marić, G. Malović, Z.L. Petrović, Eur. Phys. J. D 74, 64 (2020)

21. M. Puač, A. Dordević, Z.L. Petrović, Eur. Phys. J. D 74, $72(2020)$

22. M.C.A. Lopes, W.A.D. Pires, K.L. Nixon, R.A.A. Amorim, D.G.M. da Silva, A.C.P. Fernandes, S. Ghosh, D.B. Jones, L. Campbell, R.F.C. Neves, H.V. Duque, G. García, F. Blanco, M.J. Brunger, Eur. Phys. J. D 74, 88 (2020)

23. K. Ono, T. Oyamada, Y. Kita, M. Tachikawa, Eur. Phys. J. D 74, 89 (2020)

24. C.A. Yazejian, J.C. Straton, Eur. Phys. J. D 74, 156 (2020) 